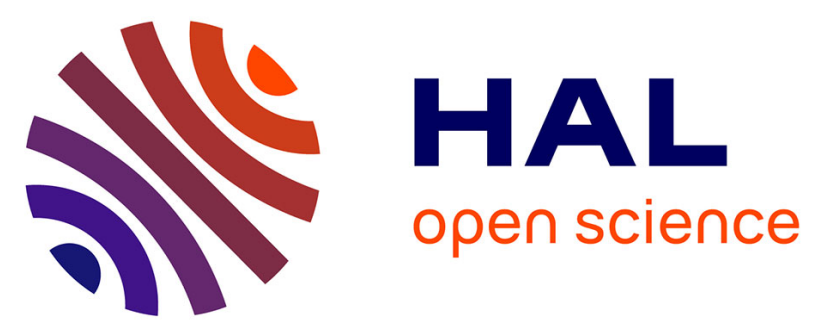

\title{
Mapping Sound Properties and Oenological Characters by a Collaborative Sound Design Approach -Towards an Augmented Experience
}

Nicolas Misdariis, Patrick Susini, Olivier Houix, Rivas Roque, Clement Cerles, Eric Lebel, Alice Tetienne, Aliette Duquesne

\section{To cite this version:}

Nicolas Misdariis, Patrick Susini, Olivier Houix, Rivas Roque, Clement Cerles, et al.. Mapping Sound Properties and Oenological Characters by a Collaborative Sound Design Approach -Towards an Augmented Experience. CMMR - Computer Music Multidisciplinary Research, Oct 2019, Marseille, France. hal-02469362

\author{
HAL Id: hal-02469362 \\ https://hal.science/hal-02469362
}

Submitted on 6 Feb 2020

HAL is a multi-disciplinary open access archive for the deposit and dissemination of scientific research documents, whether they are published or not. The documents may come from teaching and research institutions in France or abroad, or from public or private research centers.
L'archive ouverte pluridisciplinaire HAL, est destinée au dépôt et à la diffusion de documents scientifiques de niveau recherche, publiés ou non, émanant des établissements d'enseignement et de recherche français ou étrangers, des laboratoires publics ou privés. 


\title{
Mapping Sound Properties and Oenological Characters by a Collaborative Sound Design Approach - Towards an Augmented Experience.
}

\author{
Misdariis Nicolas ${ }^{1}$, Susini Patrick ${ }^{1}$, Houix Olivier ${ }^{1}$, Rivas Roque $^{1}$, Cerles Clement $^{1}$, \\ Lebel Eric ${ }^{2}$, Tetienne Alice ${ }^{2}$, Duquesne Aliette ${ }^{2}$ \\ ${ }^{1}$ STMS Ircam-CNRS-SU \\ ${ }^{2}$ Maison KRUG \\ nicolas.misdariis@ircam.fr
}

\begin{abstract}
The paper presents a specific sound design process implemented upon a collaboration with an important stakeholder of the wine (Champagne) industry. The goal of the project was to link sound properties with oenological dimensions in order to compose a sonic environment able to realise a multisensory experience during the wine tasting protocol. This creation has resulted from a large scale methodological approach based on the semantic transformation concept (from wine words to sound words) and deployed by means of a codesign method - after having shared respective skills of each field (sound and oenology). A precise description of the workflow is detailed in the paper, The outcomes of the work are presented, either in terms of realisation or conceptual knowledge acquisition. Then, future perspectives for the following of the work are sketched, especially regarding the notion of evaluation. The whole approach is finally put in the broad conceptual framework of 'sciences of sound design' that is developed and argued in the light of this study.
\end{abstract}

Keywords: sound design, codesign, taste, methodology, tools.

\section{Introduction}

The present project comes within the broad scope of crossmodal correspondences, i.e. the synesthetic associations that people tend to operate between different sensory modalities. In the literature, several studies aimed at describing or investigating the psychological mechanisms and the rationale of such associations [1]. The global aim of most of them is finally to understand how the percept in one modality can be interpreted or altered by sensory information given in another modality.

In the auditory domain, examples addressing that issue can be described, among others, with the following questions: what is the sound of a big/small or sharp/rounded objects? (e.g., the 'booba-kiki' effect studied by McCormick [2]). How does blue, red or yellow sound (e.g., the music/color correspondence, especially formalized by Kandinsky [3])? To what musical timbre a given flavor can be associated with (e.g., bitter paired with the French horn and sweet with the clarinet [4][5]). Or, quoting Charles Spence, can you taste the music? In other words, how music can influence the experience of taste, and change the personal emotional state? 
In that domain, the "complex tasting experience that is drinking wine" [6] is especially focused. Not long ago, some works studied different interactions between what we drink and what we hear, among which the effect of different music styles on basic sensations (fresh, powerful, soft) during the taste of wine [7], or the perceptual and cognitive mechanisms underlying sensory modulations due to cross-modality [8].

In that scope, we recently conducted a long-term project (2017-18) with a famous French Champagne producer: Maison Krug. The goal of the project was to realize a mapping between sound properties and oenological characters in order to guide a sound design process and create an augmented multisensory tasting experience. This experience associates sound pieces with different types of wine coming from different regions. The challenge here was to understand the oenological concepts and transcribe them into sonic properties used, afterwards, for sound composition.

To do that, we worked in collaboration with members of the Krug winemaking team (Eric Lebel, the Cellar Master or Chef de Caves, and Alice Tetienne, Winemaker) and a music composer (Roque Rivas). Moreover, the project aimed at being implemented in a dedicated room - La Salle des 400 vins - where a specific multi-channel sound diffusion system has been designed and installed in order to render spatial properties of the sound production (see Fig. 1 and Sec. 4.2 for details).
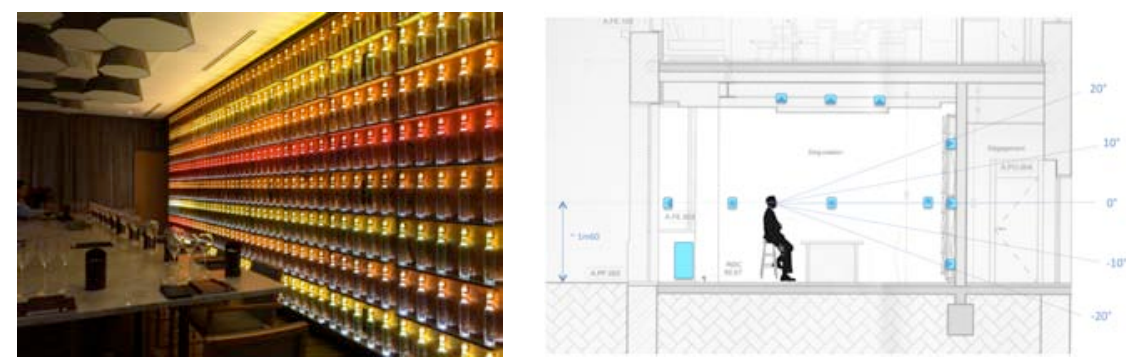

Fig. 1. Krug tasting room (Reims) equipped with a 32-loudspeaker system (right, (C).Warusfel), and the " 400 wines wall" representing the 400 'vins clairs' held in the Krug wine library (left, (CP.Susini)

The main claim of this work concerns the concept of semantic transformation and one dedicated mean to achieve it, the collaborative design approach.

Semantic transformation is a concept that has been initially formalized in the visual domain by Karjalainen and Snelders [9]. It is a translation operation that addresses the issue of transcription of intentions. It relies on the association between words attached to given intentions (e.g. Brand identity) and words able to deliver design insights. Usually, semantic transformation are supported by mediations tools [10] like moodboards, card sets, etc. and are implemented within methodological frameworks.

Collaborative design - or codesign - can precisely be a relevant method to implement semantic transformation. It is a creative methodology based on a participatory approach that started to emerge in the late nineties [11][12]. It starts from the assumption that end-users are the experts of their own activity, so that they should be actively involved in the design process [13]. It is applied in several domains going from engineering to education, through design or arts [14]. 
In the sound design domain, semantic transformation and codesign have recently been studied and applied in a long-term research within a sound branding issue. In that frame, tools and methods were developed to convey sound identity and build corporate sounds [15][16]. That work aimed at making a link between the semantic definition of a Brand (Brand-words) and semantic descriptions of sound characteristics (sound-words), in order to provide sound design recommendations.

The present study is directly inspired from this process. It tends, this time, to implement a semantic transformation between oenological identities (wine-words) and sound-words, in order to give insight to sound design composition.

The article relates the workflow implemented to conduct this project. In a first stage, two expert groups (wine and sound) learnt from each other and passed on their respective knowledge and skills (Sec. 2). In a second stage, a codesign process is implemented and resulted in mapping strategies between wine-words and soundwords (Sec. 3). In a third stage, sound-words are transformed into composed sound pieces to illustrate oenological characters and transcend the tasting experience (Sec. 4). Then, after a conclusion, we open to perspectives, especially regarding evaluation, and finally reposition the whole project into a global conceptual framework.

\section{Expertise Sharing}

During the first stage, wine and sound experts learnt from each others. This stage was motivated by the participatory methodology implemented in the project. In fact, as the protagonists involved ought to work together within a collaborative framework, it appeared necessary to share a common expertise and language to speak about wines and sounds in order to elaborate efficient recommendations for the sound creation.

\subsection{Speaking about wine}

Vocabulary used to describe wine characteristics is quite huge. This is first due to the fact that wine tasting involves several sensory modalities corresponding to different sensory operations: we look at wine (sight), we smell it (smell) and we taste it (taste).

Each step brings specific information on wine. For instance, sight informs on color, intensity or viscosity (superficial aspects), smell informs again on intensity but also on flavors, and taste informs on mouth flavors (aroma, bouquet, etc.), balance or length in mouth. Each of these dimensions gets specific terminology and represents a semantic profile by itself. The visual analysis uses words like clear/blurry, brilliant/dull, fluid/thick, pale/intense, etc., together with all the shades of red (purple, burgundy, ruby, ...) or white (colourless, yellow, golden, ...) colors. The olfactory analysis uses words like closed/opened, poor/strong, etc. together with all the families of odors. The gustatory analysis uses words like soft/nervous, bitter, flexible/heavy, fleshy, velvet, short/long, etc. together with all the families of flavors.

This massively polymorphic character of wine comes mainly from the fact that it results from complex mechanisms (terroir, soil composition, sunshine, fermentation, conservation, etc.) occurring all through the production of the liquid that will become, 
in fine, a wine or a Champagne. Precisely for Champagne - and especially in the Krug traditional process - this complexity is amplified by two elements: $i$ ) at early stage of production, a Champagne is a blend of several elementary wines - called 'vins clairs' - that the Chef de Caves mixes together to build the Cuvées of the year; ii) vinification, and especially effervescence (formation of bubbles), takes at least seven years to be completed, a period during which the liquid inside the bottle goes on evolving according to its oenological nature.

On that basis, it was really ambitious and utopic to learn how to speak and taste about wine in the frame of the project - also considering that it takes a life of learning and practice to become a professional winemaker! Nevertheless, the Krug team made the task easy by, first, opening the doors of an internal tasting session and, second, delivering a simplified (but relevant) nomenclature of their oenological references.

The tasting session was a regular meeting of the Krug team (5 winemakers) dealing with the characterization of 15 yearly samples of 'vins clairs'. This kind of session is done twice a year: from October to December, after the grape harvest, and from February to March, before the Champagne creation. It is done for all the 'vins clairs' collected in that particular year, each of them corresponding to a specific grape variety ('cepage'), vineyard ('cru'), and even parcel ('parcelle'). All the tasting notes are registered in a repository document (the 'Krug black book') that also compiles notes from previous years. It is used during the blending process as a reminder of tasting notes (gustatory sensations) that have been previously produced.

The simplified nomenclature concerned the gross regions of growing included in the overall certified Champagne Region (East of France, around the city of Reims). In fact, after the first steps of the project, it was assumed with the Chef de Caves that this level of description was a good compromise between relevance (regions with indeed specific characters) and feasibility (number of regions compatible with sound design capability and sensitivity). Thus, 10 regions were defined (e.g. 'Montagne Reims Nord', 'Cote des Blancs', etc.) and specified with words in a 3-class typology: i) oenological cursors, i.e. six words that forms a standard grid for the oenological tasting at Krug (e.g., 'structure' or 'expression'); ii) additional terms, i.e. words that can be freely added by anyone in the winemaking team (e.g., 'roundness' or 'liveliness'); ii) additional marks, i.e. words that rather correspond to metaphoric associations or affective evocations. For that latter category, it is worth noticing that musical/instrumental metaphor were often used (e.g., violin, trumpet, marimba, etc.)

Outputs of this first section was then a table of 10 regions, each described by a group of words (20 in average) structured in 3 categories going from standard dimensions to free metaphors or associations, and a sound design team - including the composer R. Rivas - that was less novice about the semantic world and process of wine tasting.

\subsection{Speaking about sounds}

The second section consisted in the dual approach: learn novices in sonic issues (the Krug team) how to listen to sound and speak about them.

For that, we started from the research undertaken by Carron (2016) in the domain of sound branding and from which the present study is inherited [16]. In fact, based 
on an analysis of several articles related to sound semantic description, Carron et al. (2017) proposed a list of common words related to sound features independent of the meaning, the process that produced the sound, or its location. Words are related to the sound itself, its acoustical characteristics and timbre features rather than illustrative analogies. Then, a lexicon - called afterwards SpeaK - that includes a list of 37 words was developed as an application displaying each word with a definition and sound examples in different categories (musical instruments, voices, environmental sounds, etc.). Within Carron's work, this operational tool was used as a training environment before a sound indexing task but also as a support for codesign sessions [17].

In the present work, the SpeaK tool was precisely used to introduce the wine experts (Krug team) to the world of sounds - and related words. Beforehand, the tool was improved in the light of the collaboration with the composer R. Rivas. A preliminary working session was organized in order to refine, and if needed extend, the lexicon.

This session actually gathered two composers (R. Rivas and Frederic Le Bel), three researchers (the 3 first authors of the article) and the sound designer who initially composed sound examples for the first version of SpeaK (Thomas Rotureau). During the session, the 22 semantic scales of the lexicon ( 15 bipolar scales +7 single words) were methodically discussed with regard to the precision of the definition and the relevance of the sound examples. According to the latter point, the two composers were previously asked to prepare and bring for this session, alternative examples able to complement or improve the existing ones.

The global outcome of this session was a new release of SpeaK with 3 new elements: $i$ ) a simpler and user-friendly interface; $i i)$ a 5-class generic structure of the sound examples (music, voice, environment, sound effects and basic synthesis); iii) if need be, new sound examples able to improve the quality of the illustration.

This current version of SpeaK was then used during a training session with the Krug team directly involved in the project: two members of the winemaking team - among whom the 'Chef de Caves' -, and the international marketing and communication director who also contributed to the collaborative process throughout the project.

The learning stage was inspired from Carron's experimental approach [16], and especially used the same training sound corpus. After some adjustments, the learning test included 4 exercises. An ownership period ( $45 \mathrm{~min}$.) by a free browsing inside the lexicon. A first individual task (20 min.) that consisted in choosing one sound among five (5-AFC) with regard to a given semantic attribute - e.g. "choose the sound that is the most fluctuant". A second individual task (20 min.) that consisted in selecting one attribute among 10 words (a reduced list of the 37 words) with regard to a given sound. Answers from these two tasks were collectively discussed in order to share everyone's view. Finally, a third collective task (20 min.) consisted in the free description of a sound with 3 to 5 words from the lexicon. This last task allows the participants to agree on the perceptive qualities associated with a term in the lexicon.

Outputs of this second second learning section was, firstly, an adopted tool to support the semantic description of sounds, that will be used thereafter supporting the codesign session (Sec. 3), and secondly, a group of wine experts provided with expert language on sound which should refine perceptive capacities, enriches sensory exploration, and facilitates information selection, identification and comparison. 


\section{Collaborative Design}

Then, after having investigated successively the wine and sound world (and words), we implemented a collaborative sound design (codesign) approach that basically consisted in going from the wine-words to the sound-words with a methodological process. This was done to give insights to the sound designer, so that he would be able to create and arrange the most relevant sound matters and forms.

\subsection{Apparatus}

The codesign environment was also transposed from Carron's work [16] and was formerly inspired by specific design approaches like Kansei [18]. Discussions were mediated by series of cardsets and the area of reflexion was materialized with a board, by analogy with a standard board game or role play. Supporting that, the SpeaK lexicon played the role of help to which anyone can refer during the session.

Three series of cardsets were built. They corresponds to the 10 wine regions, the 44 wine-words extracted from Krug terminology ( 6 oenological cursors +38 additional terms) and the 37 sound-words of the lexicon, organized in 3 gross categories (General, Morphology, Timbre). Cardsets got a color chart to make their handling easier. Moreover, two things were added to facilitate the session proceedings: blank cards to possibly introduce new terms, and a trash bin to put aside non relevant words.

The board was configured with concentric circles considering that the bull's-eye (middle) was the region and its oenological description, and that the rim could be used to organise, and in case hierarchise, the corresponding sound properties (Fig. 2).

\subsection{Protocol}

After a warm-up stage (SpeaK browsing and exercise), the codesign session went as follows: one region is chosen, the Krug team fixed its oenological properties and placed the corresponding cards on the board. Then, semantic transformation is processed by discussing and placing cards around the target. At someone's request, examples or definition attached to a particular sound-word may be given by means of the lexicon. After a while, the instrumental metaphor is delivered to revitalize the debates and launch a new round of card handling. When all the participants agreed, the semantic portrait of the region is finalized and fixed (Fig. 2).

The processing of one region took approximately 30 minutes and systematically involved the same 7 persons. One of them, from the research team, played the role of mediator who opened the discussion and led or chased up the dialogue. The whole codesign stage (for 10 regions) occurred in 2 consecutive half-days.

At the very end, the semantic portraits were reconsidered to adjust descriptions in light of global coherence. Besides, few words were instinctively added to reach affective or emotional character of each region, such as 'serious', 'happy', 'warm', 'shy', etc. This additional contribution came out of the initial methodological frame, and was motivated by the composer who felt the need to collect more sensitive and complex dimensions than the basic sound properties given by the lexicon (Fig. 2). 

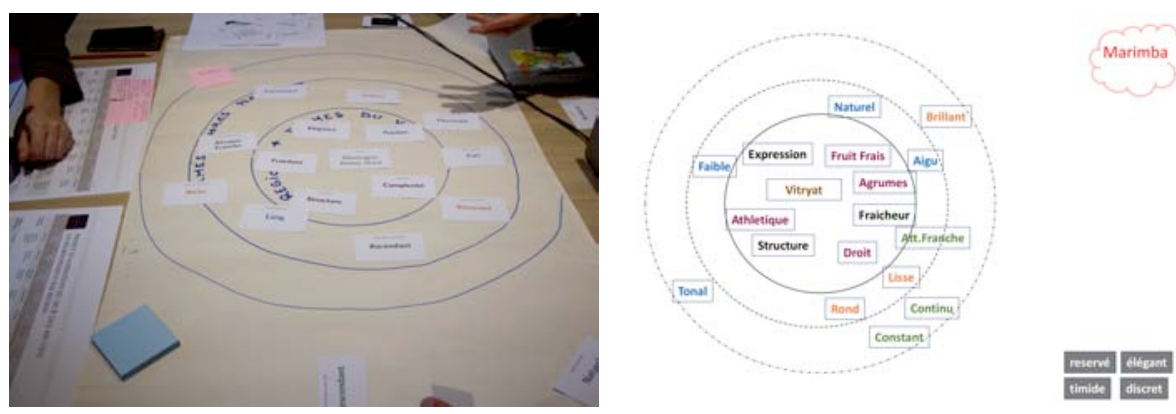

Fig. 2. Illustrative elements of the codesign sessions. The environment was formed of cardsets representing the different semantic spaces and board with concentric circles (left). At the end of each round, a semantic portrait of an oenological region is formed by associating wine-words et the center - and sound-words - in concentric circles. In each portrait, the musical metaphor is recalled and some additional affective or emotional words are added (right). (CN.Misdariis)

\subsection{Outcomes}

The main outcome of the codesign stage was 10 semantic portraits respectively of the 10 oenological regions (Figure 2 gives an example on 'Vitryat'). From that, a synthesis was done, by trying to highlight global coherence and local differences among regions. For example, we tended to reveal global characteristics related to the Montagne Reims that were common to the 3 sub-areas (Reims Nord, Sud and Ouest), and local differences to discriminate between these same areas.

A reflexive look at this approach can also form another outcome of this stage. In fact, methodological elements can be usefully extracted from this experiment. They especially concern the role and the status of the mediator, the position of the composer - as the ultimate sound expert and potential session leader - or the use of extended sound examples, especially from musical / instrumental databases, able to feed the discussion and enlighten or consolidate raw ideas. These statements may certainly help us to improve the collaborative sound design approach which seems to be a rather specific practice within the general frame of codesign (see also Sec. 5.1).

\section{Composition and Implementation}

After the apprenticeship and codesign parts (Sec. 2 \& 3), the third link of this project was mainly dedicated to composition and implementation of sonic transcriptions of concepts and words that have been handled, up to then. This part addresses two main issues: an artistic one dealing with the way to create sound sequences on the basis of words describing basic properties of sound or emotions; and a methodological one dealing with the way to transpose the work done in studio to the location where the sound design pieces were intended to be played - a fortiori if the sound diffusion system is technologically complex and massively multi-channels. 


\subsection{From description to composition}

The composition started from all the semantic tags produced during the codesign session, plus the composer's personal notes. During the composition process (nearly 2 months), R. Rivas was also fed by some listening feedbacks (from the working team) that guided him for semantic interpretations and Krug's expectations on aesthetics.

The transcription work - from sound-words to sounds - is a challenge that contains a non-negligeable part of artistic intuition and, here, that sometimes forced the composer to read into root notions - wine-words or evocations - in a personal manner. Nevertheless, he tried to rationalize his approach by translating sound-words into the three fundamentals sonic dimensions: frequency, time and space.

Frequency and time were generally informed by the basic SpeaK vocabulary and gave rise to specific spectral contents or temporal envelopes. For instance, notions like 'low/medium/high', 'crescendo/decrescendo', 'brilliant/dull' or 'fluctuating' get nearly direct correspondences in the acoustic domain. Here, the main difficulty came from the need to combine several basic notions, make them physically compatible and musically relevant. Back to root notions, as evoked above, terms like 'complexity' (oenological cursor), or 'lemony' (additional term) can respectively be related to a dense multi-layer mix of several sound textures or high-pitched and rough elements like the sound of the harmon trumpet mute that Miles Davis used to play.

On this point, the notion 'natural/artificial' used for some portraits also drove R. Rivas for the choice of specific sound synthesis paradigms. But for that, he also relied on the instrumental metaphor attached to each region by the Krug team (e.g., violin, marimba, horn, etc.). These essential references gave the color of each piece while staying subtile and integrated by means of sound transformations or complex mixing.
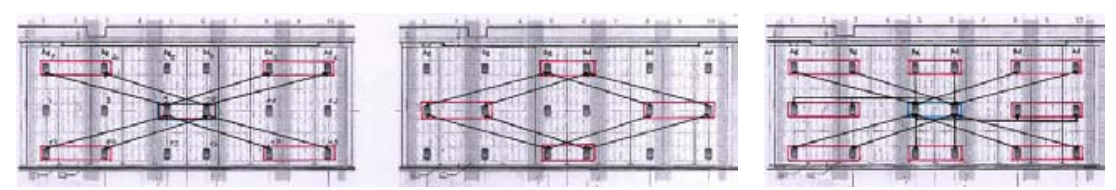

Fig. 3. Depiction of spatial sketches as stated by the composer R. Rivas in the composition phase. The background plane represents the ' 400 wines wall' and its 18 -loudspeaker device and the drawings represent sound localisation or trajectories designed inside this grid.

Space was also fully used by R. Rivas to get another degree-of-freedom in the transcription process. In fact, thanks to the multi-channel device attached to the project, a real 3D-soundscape could have been designed in order to convey sound properties like 'close/far' or illustrate complex notions like 'aerial' or 'powerful'.

These spatial effects were able to be developed either in the frontal plane of the device (18-loudseaker wall) or in the surrounding space of the room by mainly dealing with opening, localisation, dynamic trajectories (Fig. 3), or in case, immersivity and envelopment. 


\subsection{From studio work to location specific mastering}

The specificity of this project lies also in the sound diffusion system it is associated with. This is a 32-loudspeaker system, split in 3 parts: 3 lines of 6 speakers associated with the ' 400 wines wall', 6 loudspeakers placed in circle around the audience, 6 speakers integrated in the ceiling and 2-subwoofers (Fig. 1). This device - developped by Amadeus ${ }^{1}$ upon design specifications made by the Ircam/EAC team -, offers a rather unique configuration for diffusing the sound pieces created in the project. But, added to specific acoustic conditions of the tasting room (glass or plaster walls, tiles floor), it also addresses sound engineering issues related to the mastering practice

This being, in situ setting sessions were set. They mainly consisted in: $i$ ) tuning the the audio mix quality, potentially altered by resonances or reflections due to room acoustics or electroacoustic response; ii) adjusting the 3D-soundscape with regard to the room dimensions and behavior. These operations were directly done in the audio sessions made in the studio and resulted in a multi-channel bounce for each of the 10 pieces, dedicated to be played back by a direct-to-disk device.

This part of the work points out a crucial practice in sound design: the location specific mastering. In fact, mastering is the final step of standard music production that aims at optimizing listening conditions in as many diffusion systems as possible. Sound design practices are commonly faced at specific mastering issues because of the diversity of sound devices usually used in this domain - from few (cheap) buzzers or loudspeakers placed in non conventional rooms (e.g. an automotive cockpit) to a lot of diffusion sources placed in large hall, such as a museum or a commercial hall ${ }^{2}$. One way to deal with this problem is to use audio simulation strategies based on 3D impulse response (IR) measurements that - by a deconvolution process - are able to render the effect of a given source diffused in the given room.

Presently, this virtual approach was not implemented for sake of time and project phasing. Instead, the composer and sound engineers (Clement Cerles and Colin Lardier), worked in studio either in a standard monitoring device or with a pseudo'400 wines wall'. This system was built on purpose with similar unit sound devices and complied with the real volumic dimensions (wall's area, room's volume, etc.). In addition, as mentioned above, location specific mastering sessions were set and resulted in several modifications (EQs, internal balance of the mix, panoramic, tight filtering, etc.) that significantly improved the listening quality of the sound pieces.

\section{Conclusions and Perspectives}

To conclude, we conducted a long term project (nearly 2 years) that led us into the unexplored territory of wine industry and Champagne know-how. The main goal of the project was to design sound pieces informed by the knowledge of semantic correspondences between wine and sound worlds.

\footnotetext{
${ }^{1}$ http://amadeusaudio.fr/en/

2 https://www.ircam.fr/article/detail/mastering-hors-du-studio-trois-experts-en-design-sonore-decryptentdes-nouvelles-pratiques-1/
} 
The research and creation team was formed with researchers in auditory perception and sound design, a composer and a sound engineer who also played the role of a computer music designer [19]. The industrial collaboration was mainly interfaced with the Krug winemaking team and the marketing/communication department.

The project implemented the concept of semantic transformation and unfolded a participatory approach within a collaborative design (codesign) process. Moreover, it leaned on a methodological tool - previously developed and improved in the present frame: a sound lexicon (SpeaK) built as a dictionary collecting the major words used to describe sound properties, together with definitions and sound examples.

Within this frame, the project got four main stages in order to successively learn how to speak about wines, speak about sounds and collectively implement the semantic transformation from wine-words to sound-words. The fourth stage was dedicated to sound design (creation) and aimed at translating sound-words into sounds and musical composition that finally resulted in ten 1-min sound pieces diffused by a multi-channel sound device placed in a dedicated room: the Krug tasting room.

\subsection{Perspectives}

In the light of its originality and complexity, the Krug's project brings into front an emblematic approach. As a research process, it leads to open perspectives that should be further investigated in order to complement the project outputs. These perspectives mainly concern two components: codesign methodology and evaluation. As a sound design research, this project may also contribute to enhance our knowledge on the discipline and be part of a conceptual framework called sciences of sound design [20].

The codesign methodology applied to sound design seems to be quite encouraging and promising. As in its first implementation [16], the lexicon that supported the approach confirmed to be an efficient and relevant tool able to help communication and understanding on sounds. Nevertheless, the current codesign implementation showed some weakness that should be investigated and, may be, improved.

For instance, whereas the preliminary training exercises appeared to be unmissable, some uncertainties arose according the relevancy of the sound examples dedicated to these exercises and especially their ability to express just one basic property. Attention must be paid on the selection of these sounds and their polysemic content.

This precise issue is also addressed to the lexicon itself. In fact, on behalf of its rather 'encyclopedic' status, SpeaK must provide irrevocable and unequivocal specimens of sound examples illustrating sound attributes. This effort goes through the re-design of most of all examples from all categories. This work has yet started with the voice category by means of a recording campaign conducted by the composer R. Rivas; it will soon produce high quality and controlled vocal samples.

Indeed, concerning SpeaK, a more conceptual issue appeared during the Krug experiment: the fact that the list of pre-defined words were not sufficient enough to describe an oenological identity and that the composer needed high level descriptions (emotions, evocations, character) to be able to translate ideas into composition.

Finally, and more globally, we observed the fact that the experimental apparatus (board, cardsets, lexicon) prevented from describing dynamic changes of a semantic portrait as it often occurs in sound perception, but also wine tasting! This may force 
us to imagine new paradigms that would also consider the temporal dimension of sounds which is not equally relevant in other domains (e.g. graphics).

On the other hand, whereas the PDS research group used to promote a 3-step sound design model (Analysis, Creation, Validation) [21], the evaluation stage is, right now, rather completely missing from the project proceedings - except few informal (and positive) feedbacks from the first tasting sessions at Krug. This point addresses an interesting and controversial issue that the project itself could help to investigate.

In fact, this asks the following fundamental questions: why should we evaluate and how can we proceed an evaluation? A rational answer to the first question could be: to verify the match between solutions and specifications, or to ensure the usefulness, usability, and desirability of the user experience produced by the solutions [22]. As for evaluation procedures, they should to be inspired, as usual, by the experimental psychology discipline with physiological, perceptual or cognitive measurements.

But, transposed to the current use case, the previous rationale appears to be more complex to argue and implement. In fact, in that case, the main specification to evaluate could be the perception of the wine characters into the sound composition. In other words, does one recover the basic oenological attributes of a region into a 1-min sound piece experience? Or more globally, is the semantic transformation finally valid, i.e. does it help the composer to create a relevant sound content and the listener to recognize the wine identity that intended to be illustrated? Or, alternatively, what does all of this bring to the tasting experience? All these questions address methodological issues in terms of experiment (what / how to measure?) but also in terms of contextualization (how to put the participants into controlled - and ethically acceptable - tasting conditions?). These issues form a work-in-progress reflexion that we hope to investigate and implement in a near future.

By listing all these outcomes and perspectives, we can observe that the Krug project brings considerable knowledge on the sound design discipline itself, its protagonists, its process and even its production. In that way, and even if it initially targeted a direct application - sound pieces composition for a tasting experience -, this project could finally be seen as a potential research project implementing a research-throughdesign approach that aims at producing knowledge instead of only solutions [23].

This precisely comes into the conceptual frame we recently tried to make emerge and promote, in accordance with the three research loci of Nigel Cross' formalization on design research: people, process and products [24]. In fact, transposed to the discipline of sound design, we look at laying the foundations of sciences of sound design that will investigate simultaneously the character of the sound designer, the sound design process, tools or methods and the status of the designed sound, i.e. what sound design produces in fine [20]. Then, to some degree, we can expect that the present project may have helped - and will help - to inform this approach and, by quoting Cross (2001) [25] give some elements to answer to the seminal question: is there a designerly way of knowing, thinking and acting in sound design?

Acknowledgments. The authors - namely the Ircam group - are sincerely thankful to Maison KRUG (Maggie Henriquez, and the last three authors of this paper) for their fruitful collaboration and flawless welcome. All authors would also like to thanks Cyril Beros, Jeremie Henrot (Ircam PROD), Olivier Warusfel (Ircam-STMS EAC), Gaetan Byk (Amadeus) and Emmanuelle Zoll for their contributions to the study. 


\section{References}

1. Spence, C. (2011). Crossmodal correspondences: A tutorial review. Attention, Perception, \& Psychophysics, 73(4), 971-995.

2. McCormick, K., Kim, J., List, S., \& Nygaard, L. C. (2015, July). Sound to Meaning Mappings in the Bouba-Kiki Effect. In CogSci (Vol. 2015, pp. 1565-1570).

3. Kandinsky, W. (1971). Du spirituel dans l'art. Denoël/Gonthier.

4. Crisinel, A.-S., Spence, C. (2010). As bitter as a trombone: Synesthetic correspondences in nonsynesthetes between tastes/ flavors and musical notes. Attention, Perception, \& Psychophysics, 72, 1994-2002.

5. Crisinel, A.-S., Spence, C. (2010b). A sweet sound? Exploring implicit associations between basic tastes and pitch. Perception, 39, 417-425.

6. Spence, C., \& Wang, Q. J. (2015). Wine and music (II): can you taste the music? Modulating the experience of wine through music and sound. Flavour, 4(1), 33.

7. North, A. C. (2012). The effect of background music on the taste of wine. British Journal of Psychology, 103(3), 293-301.

8. Spence, C., \& Wang, Q. J. (2015). Wine and music (I): on the crossmodal matching of wine and music. Flavour, 4(1), 34.

9. Karjalainen, T. M., \& Snelders, D. (2010). Designing visual recognition for the brand. Journal of Product Innovation Management, 27(1), 6-22.

10.Boujut, J. F., \& Blanco, E. (2003). Intermediary objects as a means to foster co-operation in engineering design. Computer Supported Cooperative Work (CSCW), 12(2), 205-219.

11.Kvan, T. (2000). Collaborative design: what is it?. Automation in construction, 9(4).

12.Sundblad, Y. (2010, October). UTOPIA: Participatory Design from Scandinavia to the World. In IFIP Conference on History of Nordic Computing. Springer, Berlin, Heidelberg.

13.Darras, B. (2017). Design du codesign Le rôle de la communication dans le design participatif. MEI Médiation et information, $n$ 40: Design et communication, 141.

14.Côté, N., Dubus, B., Fruleux, A., \& Roche, C. (2014). Utilisation du Codesign dans la formation d'ingénieurs: exemple de projets en acoustique. In Proceed. CFA 2014.

15.Carron, M., Dubois, F., Misdariis, N., Talotte, C., \& Susini, P. (2014, October). Designing sound identity: providing new communication tools for building brands corporate sound. In Proceedings of the 9 th audio mostly: a conference on interaction with sound (p. 15). ACM.

16.Carron, M. (2016). Méthodes et Outils pour Définir et Véhiculer une Identité Sonore (Doctoral dissertation, Université Paris 6 (UPMC)).

17.Carron, M., Rotureau, T., Dubois, F., Misdariis, N., \& Susini, P. (2017). Speaking about sounds: a tool for communication on sound features. Journal of Design Research , 15 (2)

18.Gentner, A., Bouchard, C., Badoil, A., \& Favart, C. (2014, June). Kansei Cards: A Visual Tool Supporting the Investigation; Discussion; and Representation of the Kansei-Related Intentions of a Product to be Designed. In KEER2014 Proceedings. Linköping; Sweden.

19.Zattra, L., \& Donin, N. (2016). A questionnaire-based investigation of the skills and roles of Computer Music Designers. Musicae Scientiae, 20(3), 436-456.

20.Misdariis, N. (2018). Sciences du design sonore. Approche intégrée du design sonore au sein de la recherche en design. HDR thesis, Université de Technologie de Compiègne.

21.Susini, P., Houix, O., \& Misdariis, N. (2014). Sound design: an applied, experimental framework to study the perception of everyday sounds. The New Soundtrack , 4 (2).

22.Robare, P. (2009). Sound in Product Design (Doctoral dissertation, Master thesis in Interaction Design. Pittsburgh, USA: Carnegie Mellon University School of Design).

23.Findeli, A. (2015). La recherche-projet en design et la question de la question de recherche: essai de clarification conceptuelle. Sciences du design, (1), 45-57.

24.Cross, N. (2006). Designerly ways of knowing . Springer London.

25.Cross, N. (2001). Designerly ways of knowing: Design discipline versus design science. Design issues , 17 (3), 49-55. 